\title{
Oficinas de Robótica Livre Educacional: relato de experiência de um projeto de inovação pedagógica
}

Ivaldir de Farias Junior - https://orcid.org/0000-0001-9860-8206 ${ }^{1}$

Jeferson Kenedy Morais Vieira - https://orcid.org/0000-0003-1679-88572

\section{RESUMO}

Este relato objetiva apresentar as atividades desenvolvidas em um projeto de inovação pedagógica, aprovado em um edital de fomento da Universidade de Pernambuco (UPE) para alunos e professores de ensino médio e universitário. Foram realizadas três oficinas com estudantes e uma com professores universitários, totalizando quatro oficinas. As oficinas proporcionaram aos participantes reflexões sobre o ensino e aprendizagem de forma lúdica e dinâmica, bem como despertou o pensamento crítico, trabalho em equipe com foco em cooperação e colaboração, com vistas a resolver problemas reais do dia a dia. Por fim, o projeto promoveu aos participantes o primeiro contato com a robótica livre, diminuindo a distância entre o participante e o conhecimento acerca da temática, além de gerar as vivências e reflexões acerca da prática e do conhecimento adquirido sobre a temática.

Palavras-chave: robótica livre; educação; inovação pedagógica.

1 Pós-Doutor em Ciência da Computação. Docente na Universidade de Pernambuco - UPE, Campus Garanhuns. E-mail: ivaldir.farias@upe.br

${ }^{2}$ Mestre em Engenharia de Software, Doutorando em Ciência da Computação pela UFPE. Docente na Universidade Federal do Ceará - UFC, Campus Quixadá. E-mail: jefersonkenedy@ufc.br 


\section{Educational Open Robotics Workshops: experience report of a pedagogical innovation project}

This report aims to present the activities developed in a pedagogical innovation project for high school and university students and teachers. Three workshops were held with students and one with university professors, totaling four workshops held in the project. The workshops provided participants moments of reflection on teaching and learning in a playful and dynamic way, as well as awakened in them critical thinking, teamwork with a focus on cooperation and collaboration to solve real day-to-day problems. Finally, the project made it possible for the participants to have a first contact with free robotics, therefore reducing the distance between them and the knowledge about the theme, in addition to generating experiences and reflections about the practice and knowledge acquired on the subject.

Keywords: robotics; education; pedagogical innovation.

\section{INTRODUÇÃO}

0 presente estudo consiste em um relato de experiência de atividades realizadas em um projeto de inovação pedagógica na área de robótica livre educacional, o qual teve por objetivo propiciar discussão e reflexão, desenvolvimento do pensamento crítico, além de apresentar para os participantes uma forma mais lúdica e dinâmica sobre o ensino e aprendizagem para qualquer área do saber. Tal projeto teve outros objetivos, tais como: capturar a percepção dos desafios dos professores sobre a aplicação da robótica em sala de aula, além de incentivar o trabalho em equipe por meio da cooperação e colaboração na resolução de problemas cotidianos.

Há alguns anos, a robótica apresenta grande potencial como ferramenta interdisciplinar, visto que a construção de protótipos, em geral, faz com que o aluno questione e seja capaz de relacionar diferentes conhecimentos e aptidões, de forma a solucionar um problema. A busca por soluções estimula o espírito investigativo, fortemente motivado pela curiosidade, e permite que o aluno extrapole os conhecimentos individuais de cada disciplina (SANTOS et al., 2010). A robótica vem causando grande turbulência, movimento e impacto na nossa sociedade por trazer inovações em diversas 
áreas do saber. Os assuntos normalmente abordados em robótica exploram vários conceitos aprendidos em diversas áreas do conhecimento, tais como matemática, física, eletrônica, informática, dentre outras.

Nesse contexto, a Robótica Educacional ganha força por se tratar da aplicação da robótica na área pedagógica, com o objetivo de disponibilizar aos alunos a oportunidade de criar soluções voltadas ao mundo real, de forma a possibilitar o aprendizado de forma dinâmica e estimulante (SANTOS et al., 2010). Por meio da robótica educacional livre os alunos podem descobrir novos horizontes no campo da imaginação, ideação e na aplicação de conceitos adquiridos em sala de aula, com vistas a resolver problemas reais (LUX, et al., 2007; SANTOS et al., 2010).

A robótica educacional não é algo novo, ela surgiu na década de 1960, quando seu pioneiro Seymour Papert (1994) estava desenvolvendo sua teoria sobre o construcionismo. Seymour Papert defendia o uso do computador nas escolas como um recurso atrativo, dinâmico para conquistar a atenção dos alunos (BORTOLINE, 2012). Com a robótica inserida no meio educacional podemos relacionar diversos conteúdos, de várias áreas que podem ser potencializados no que tange o ensino-aprendizagem, visando um ensino baseado em problemas reais utilizando PBL (Problem Based Learning).

De acordo com Araújo (2014) a utilização de ferramentas que permitam o aprimoramento dos assuntos abordados pelos educadores é um fator determinante na aprendizagem. Pereira (2015) afirma que o ensino da robótica, pode propiciar ambientes diferenciados e inovadores de aprendizado que estimulam o desenvolvimento da criatividade.

O projeto de inovação pedagógica que é uma iniciativa da UPE para projetos vivenciados que se articulem a solução de problemas do cotidiano, cuja natureza pode ser institucional, empreendedora, tecnológica, industrial ou comunitária visando à melhoria do processo educacional. Esse projeto ocorreu durante um ano e meio, entre 2019 e 2021. A princípio, o projeto foi concebido para ser executado em um ano, porém, com o contexto da crise sanitária (Pandemia da Covid-19) o mesmo foi estendido e adaptado ao contexto híbrido e remoto, respeitando os protocolos recomendados pela Organização Mundial da Saúde (OMS), bem como as orientações do Ministério da Saúde.

A construção do projeto se deu em razão da UPE - Campus Garanhuns manifestar o interesse em ações da aplicação da Robótica Livre para seus alunos por meio do Laboratório de Tecnologias Digitais da Informação e Comunicação (LATIDIC). A partir do diálogo com os atores desse espaço, professores, alunos e acadêmicos do Curso de Licenciatura em Computação, em parceria com uma Associação de Empresas de Tecnologia - Softex Recife, criaram e desenvolveram as Oficinas de Robótica Livre 
Educacional (ORLE). Essas foram divulgadas para todos os estudantes da UPE e nas Escolas Técnicas Federais e Estaduais da região, tendo sido marcado o dia e o horário para o início das atividades.

Assim, foram realizadas quatro oficinas, cada uma com duração de vinte horas, com dois encontros semanais com duração média de três horas por encontro, mediadas por professores da UPE e estudantes universitários dos cursos de computação/engenharia que ministraram as oficinas. Foram executadas três oficinas com alunos universitários e do ensino médio, e uma outra oficina para professores, totalizando quatro oficinas no projeto. No total, 106 alunos se inscreveram nas oficinas. Entretanto, somente 75 participaram e finalizaram as oficinas.

A seguir, são apresentadas as atividades desenvolvidas nesse projeto de inovação pedagógica com alunos e professores. As oficinas visaram fomentar o senso crítico e a visão investigativa no processo de aprendizagem da oficina. Neste sentido, foi proposta aos participantes a investigação de possíveis problemas reais no meio em que eles transitam para que pudessem propor soluções em função dos temas abordados em sala e também de outros conhecimentos. Para a efetiva realização das oficinas e concepção de projetos relevantes criou-se um processo para auxiliar e nortear a execução de cada oficina.

\section{Procedimentos:}

Antecipação: Apresentar aos educandos projetos funcionais, artefatos robóticos, entre outros que fazem parte do conteúdo ministrado na oficina.

Instrução direta: Apresentar imagens, símbolos, instruções orais ou adaptadas, seja nos conteúdos ou em dinâmicas para que a informação seja entendida por todos.

Prática guiada: Suporte do educador sempre no início de cada atividade prática e quando solicitado.

Verificação do entendimento: Realização de atividades práticas ou levantamento de problemáticas em função do tema da aula para que os educandos possam, de forma lúdica, realizar a atividade ou apresentar uma possível solução.

Encerramento: Diálogos sobre o tema da oficina e o dia a dia dos educandos.

Na primeira oficina, houve a inscrição de 44 alunos. Dos inscritos, 35 eram alunos da UPE dos diversos campus (Exemplo: Multicampi Garanhuns, Caruaru, Benfica dentre outros) e 9 eram alunos de outras universidades. A oficina teve 20 horas de aula e mais a execução de um projeto com posterior apresentação para uma banca avaliadora. A Figura 1 ilustra uma das soluções implementadas em um dos projetos executados. As aulas ocorreram duas vezes na semana no formato online conforme Figura 2. Nesta oficina 
foram formados sete grupos que trabalharam os seguintes temas nos seus respectivos projetos (duas equipes trabalharam com o tema automação residencial):

1. Sistema de irrigação inteligente;

2. Projeto de acessibilidade para deficientes visuais;

3. Desperdício de energia;

4. Sensor de luz ambiente acionado por presença;

5. Acionamento de sistemas por controle;

6. Automação residencial.

Figura 1 - Solução de acessibilidade para deficientes visuais implementada por uma das equipes da primeira oficina

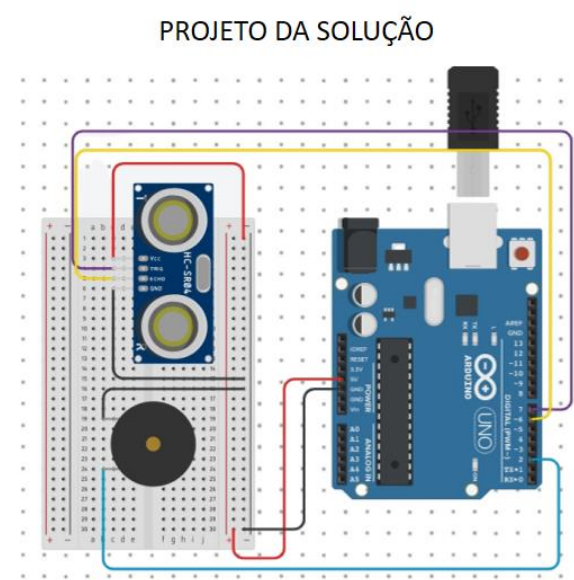

Fonte: Acervo do projeto, 2020.

Figura 2 - Primeira oficina online de robótica livre aplicada à educação

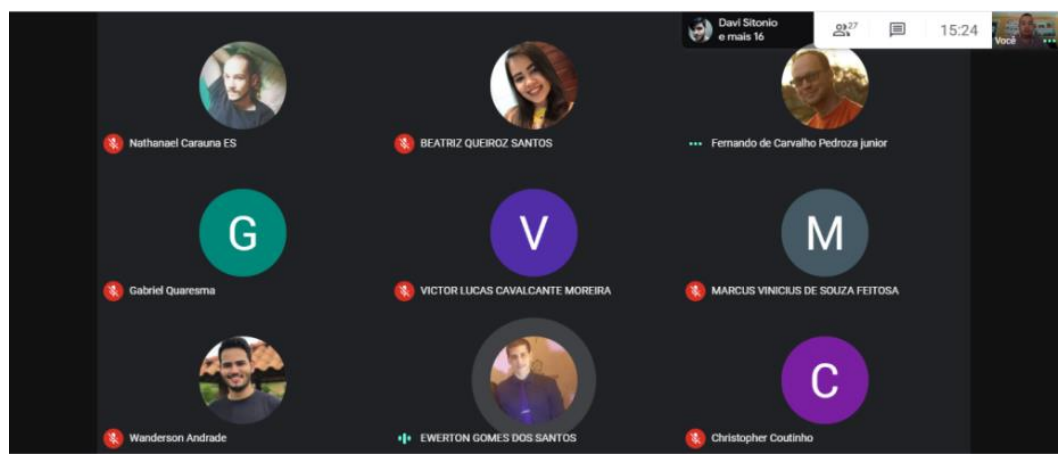

Fonte: Acervo do projeto, 2020. 
Na segunda oficina, o foco foi capacitar os professores para utilizarem a robótica como ferramenta educacional. Tiveram 11 professores inscritos. Dos inscritos, 4 eram professores da UPE Multicampi Garanhuns e 7 eram professores de outras universidades. A oficina teve 20 horas de aula e mais a execução de um projeto com posterior apresentação para uma banca avaliadora. As aulas ocorreram duas vezes na semana no formato online, conforme a Figura 3. Nesta oficina foram formados três grupos que trabalharam os seguintes temas nos seus respectivos projetos:

7. Iluminação acionada via bluetooth;

8. Acionamento (abertura/fechamento) de portas e portões via wi-fi;

9. Sensor de luminosidade em ambientes domésticos.

Figura 3 - Segunda oficina online de robótica livre aplicada à educação

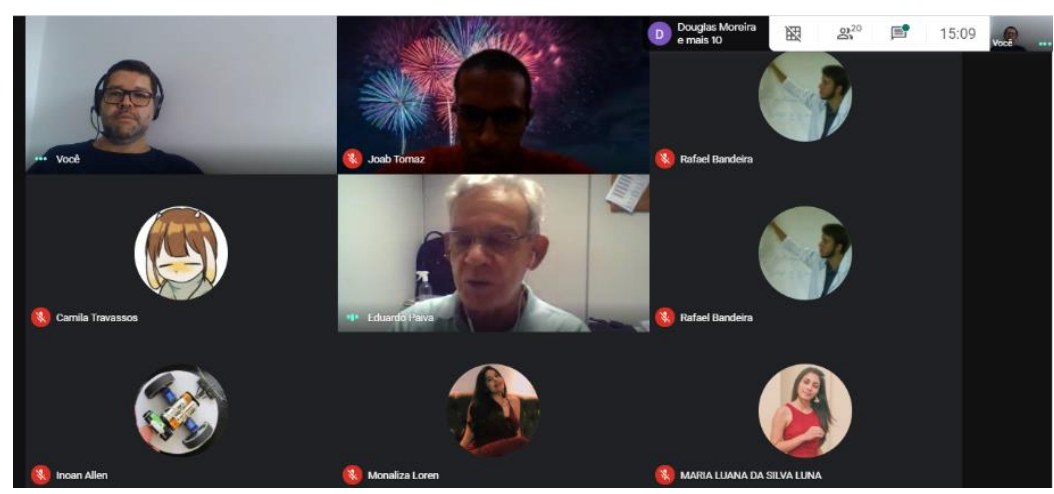

Fonte: Acervo do projeto, 2020.

Na terceira oficina, houve a inscrição de 26 alunos. Dos inscritos, 15 eram alunos da UPE dos diversos campus (Exemplo: Multicampi Garanhuns, Caruaru, Benfica dentre outros) e 11 eram alunos de outras universidades. A oficina teve 20 horas de aula e mais a execução de um projeto com posterior apresentação para uma banca avaliadora. As aulas ocorreram duas vezes na semana no formato online. Nesta oficina foram formados quatro grupos que trabalharam os seguintes temas nos seus respectivos projetos:

10. Casa Inteligente;

11. Sensor traseiro e dianteiro para carros;

12. Campainha com alarme de led para pessoas com surdez;

13. Semáforos para pedestres. 
Na quarta e última oficina, 25 alunos se inscreveram. Todos os alunos eram da Escola Técnica Estadual Ariano Vilar Suassuna da cidade de Garanhuns/PE. A oficina teve 20 horas de aula e mais a execução de um projeto com posterior apresentação para uma banca avaliadora. As aulas ocorreram duas vezes na semana no formato híbrido conforme a Figura 4. Nesta oficina foram formados três grupos que trabalharam os seguintes temas nos seus respectivos projetos:

14. Chuveiro inteligente;

15. Dispenser de álcool gel;

16. Sino Automático / Alarme de troca de aula.

Figura 4 - Quarta oficina executada no formato híbrido sobre robótica livre aplicada a educação
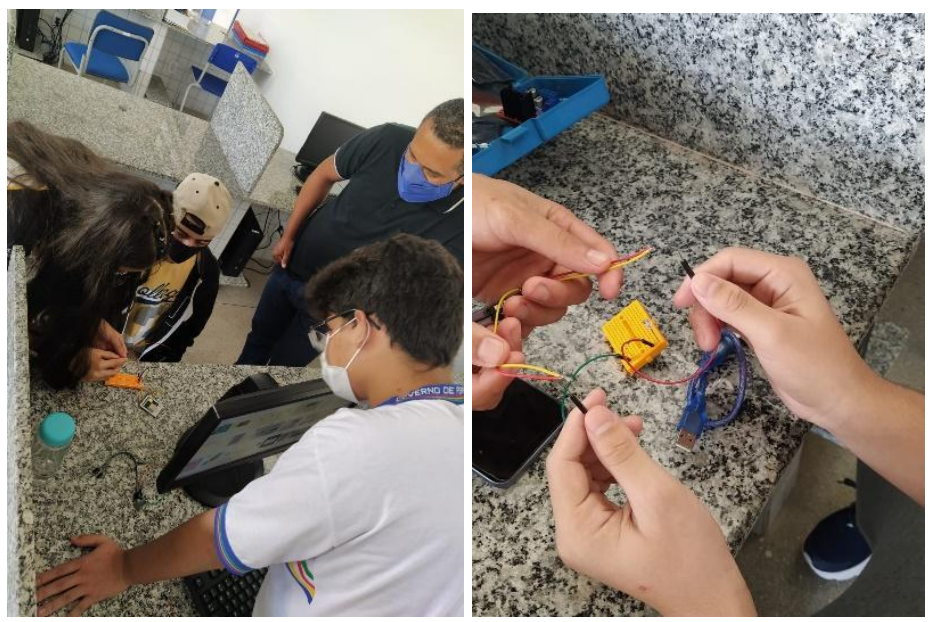

Fonte: Acervo do projeto, 2021.

Entende-se que as oficinas atenderam aos objetivos propostos, pois proporcionaram aos participantes um espaço para que eles se colocassem como protagonistas, ou seja, eles estavam buscando dar soluções para problemas reais. Os participantes avaliaram positivamente o projeto, enfatizando que tiveram espaço para falar, refletir, pensar, debater, tirar dúvidas e ainda receber mentoria, bem como interagir com outras pessoas de diferentes culturas e pensamentos.

Após a execução das oficinas, os alunos foram convidados a responderem uma pesquisa de satisfação por meio de um questionário online. Em geral, os participantes consideraram que foram poucos encontros, entretanto, as oficinas conseguiram alcançar o objetivo proposto. Além disso, os participantes sugeriram que as oficinas fossem realizadas com maior carga horária, buscando dar continuidade com assuntos mais 
avançados. A Figura 5 apresenta alguns comentários dos participantes ao término das oficinas:

Figura 5 - Comentários sobre as oficinas

Participante 1: "Essa oficina me inspirou e a cada dia vem me motivando a continuar buscando conhecimento além do querer em agir."

Participante 2: "Ampliou meus conhecimentos, e fortaleceu ainda mais a minha vontade sobre qual área de conhecimento escolher para a minha vida profissional."

Participante 3: "Este curso influenciaráem váriasáreas, na minha faculdade e na profissão que eu almejo."

Participante 4: "Influenciará no meu aprendizado, pois com esse curso, eu pude aflorar o meu cérebro e meus conhecimentos."

Participante 5: "O conhecimento adquirido foi excelente!"

Participante 6: "Tenho planos em implantar a robótica na área que eu pretendo seguir."

Participante 7: "Poderei aplicar meus conhecimentos na nossa equipe de robótica e desenvolver projetos que solucionem problemas do cotidiano."

Participante 8: "Ele foi o primeiro contato que tive com eletrônica. Desta forma eu tive a oportunidade de despertar o meu interesse pela área."

Participante 9: "Ajudou-me a ter mais certeza sobre a área que desejo seguir como carreira profissional."

Participante 10: "Sempre que nós adquirimos conhecimentos isso sempre nos faz ter novas experiências e

ideias."

Participante 11: "Esta oficina ajudará em diversos meios, como buscar a se aperfeiçoar mais na área da

robótica, da computaçãoe influenciar outras pessoas a desenvolver competências psicomotoras."

Fonte: Acervo do projeto, 2021.

Diante deste contexto, ao término das oficinas, evidenciou-se, que essas primeiras experiências extraídas do projeto, contribuíram para a formulação de projetos de extensão em parceria com escolas técnicas e a universidade UPE - campus Garanhuns, uma vez que se percebeu o impacto positivo do ensino de robótica livre educacional e por este motivo nasceu a vontade e necessidade de desenvolver ações contínuas, desta vez, especificamente no ecossistema da cidade de Garanhuns.

As experiências adquiridas neste projeto contribuíram com o despertar para a prática profissional dos participantes, bem como com a compreensão da temática por meio das discussões constantes sobre a utilização da robótica como ferramenta pedagógica. A interação dialógica neste projeto se deu por meio da participação de estudantes de ensino médio/técnico, estudantes de graduação e professores de ensino médio e superior como alunos das oficinas, houve ainda a participação de empresários como membros das bancas de avaliação dos projetos.

A interdisciplinaridade pode ser percebida por meio da variedade de temáticas utilizadas nos projetos, tais como, engenharia, computação, educação, biologia, questões sociais, dentre outras. No que diz respeito à relação com a pesquisa, alguns trabalhos de pesquisa (em andamento) também emergiram a partir deste projeto de extensão, dentre eles, é possível citar a realização de um survey (considerado um tipo de investigação quantitativa que visa coletar dados e informações a partir de características e opiniões de 
grupos e/ou indivíduos) com os participantes das oficinas na tentativa de identificar os benefícios e desafios da adoção de robótica livre nas escolas e/ou nas universidades.

Este projeto também contribuiu com a formação dos discentes que participaram como membros da equipe executora que atuaram em conjunto com os professores, pois estes eram, em sua maioria, estudantes do curso de Licenciatura em Computação da UPE, e com o projeto tiveram a oportunidade de vivenciar na prática a utilização de um recurso lúdico para o ensino de computação.

Por conseguinte, as oficinas conseguiram alcançar o propósito desta iniciativa ao explicitar em cada um dos projetos apresentados pelas equipes como trabalho de conclusão, o alinhamento com o objetivo geral da proposta deste projeto de inovação pedagógica.

Vale salientar que todos os projetos foram realizados com fins didáticos e educacionais, buscando materializar a solução em nível de protótipo para resolver problemas reais. Ao longo da execução das oficinas, foi possível calibrar práticas que contribuem para aprimorar as estratégias de ensino e a efetiva aprendizagem para utilização da robótica livre como ferramenta pedagógica.

Conclui-se que devido à crise sanitária (Pandemia da Covid-19) houve o desafio de planejar, executar, verificar e promover as melhorias para execução de cada oficina. Entretanto, ao longo de cada ciclo, foi possível obter experiências que contribuíram sistematicamente sobre o tema para melhorarmos. Acredita-se que este projeto teve impacto social positivo na vida dos participantes, e por este motivo se faz necessário que o mesmo seja replicado em outros cenários, com o intuito de despertar, estimular e mudar o mindset (forma de pensar) de todos que possam ter contato com a robótica livre educacional.

\section{REFERÊNCIAS}

ARAÚJO, Patrícia Maria Caetano. Um olhar docente sobre as tecnologias digitais na formação inicial do pedagogo. 2004. 161f. Dissertação (Mestrado em Educação) Programa de Pós-Graduação em Educação, Pontifícia Universidade Católica de Minas Gerais, Belo Horizonte, 2004.

BORTOLINE, Angelica. et al. Reflexões sobre o uso das tecnologias digitais da informações e da comunicação no processo educativo. Revista destaques acadêmicos, Lajeado, v. 4, n. 2, p.141-150, 2012.

LUX, Beatriz et al. Formação prática do licenciando em computação para trabalho com robótica educativa. Brazilian Symposium on Computers in Education (Simpósio Brasileiro de Informática na Educação - SBIE), [S.l.], p. 340-349, nov. 2007. ISSN 2316-6533. Disponível em: <https://www.br- 
ie.org/pub/index.php/sbie/article/view/583>. Acesso em: 24 out. 2021. doi: http://dx.doi.org/10.5753/cbie.sbie.2007.340-349.

PAPERT, Seymour. A Máquina das Crianças: Repensando a escola na era da informática. Porto Alegre: Artes Médicas, 1994.

PEREIRA, Márcio Lúcio Dias. Projetos de robótica educacional como apoio ao ensino de matemática e física: criando um protótipo de robô controlado por sensor de luminosidade. 2015. 27f. Dissertação (Mestrado no Ensino de Ciências e Matemática) Programa de Mestrado Profissional em Ensino de Ciências e Matemática, Universidade Cruzeiro do Sul, São Paulo, 2015.

SANTOS, Franklin Lima; NASCIMENTO, Flávia Maristela S.; BEZERRA, Romildo M. S.. REDUC: A Robótica Educacional como Abordagem de Baixo Custo para o Ensino de Computação em Cursos Técnicos e Tecnológicos. Anais Workshop de Informática na Escola, [S.l.], p. 1304-1313, jun. 2010. ISSN 2316-6541. Disponível em: <https://www.br-ie.org/pub/index.php/wie/article/view/2053>. Acesso em: 24 out. 2021. doi: http://dx.doi.org/10.5753/cbie.wie.2010.1304-1313.

Os autores declaram participação na autoria conforme a Taxonomia CRediT da Casari (vide https://casrai.org/)

\begin{tabular}{|c|c|c|c|c|c|c|}
\hline Conceituação & Metodologia & Software & Validação & Análise formal & Investigação & Recursos \\
\hline$[1] /[2]$ & [1] & & {$[1] /[2]$} & & [1] & [1] \\
\hline Curadoria & Primeira redação & Revisão/edição & Visualização & Supervisão & Admin. projeto & Financiamento \\
\hline$[1] /[2]$ & [1] & [2] & {$[1] /[2]$} & & [1] & [1] \\
\hline
\end{tabular}

